\title{
Correction to: Adult-onset vanishing white matter in a patient with EIF2B3 variants misdiagnosed as multiple sclerosis
}

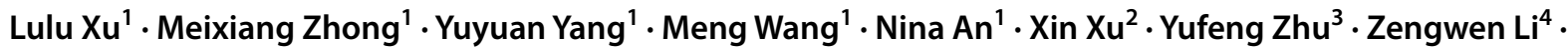 \\ Huili Chen ${ }^{5} \cdot$ Renliang Zhao ${ }^{2} \cdot$ Xueping Zheng ${ }^{1}$ \\ Published online: 21 December 2021 \\ (c) Fondazione Società Italiana di Neurologia 2021
}

\section{Correction to: Neurological Sciences (2021) \\ https://doi.org/10.1007/s10072-021-05710-4}

Originally, figure 4 has some unnecessary parts when posted online. Author wished to update and replace the figure with the correct image.

The original article has been corrected.

Publisher's Note Springer Nature remains neutral with regard to jurisdictional claims in published maps and institutional affiliations.

The original article can be found online at https://doi.org/10.1007/ s10072-021-05710-4.

Renliang Zhao

zhrenliang@163.com

$\triangle$ Xueping Zheng

simplexueping@163.com

1 Department of Geriatric Medicine, the Affiliated Hospital of Qingdao University, 16 Jiangsu Road, Qingdao 266000, Shandong, China

2 Department of Neurology, the Affiliated Hospital of Qingdao University, 16 Jiangsu Road, Qingdao 266000, Shandong, China

3 Department of Graduate School, Qinghai University, Xining 810016, Qinghai, China

4 Department of Radiology, Gaomi Municipal Hospital, Gaomi 261500, Shandong, China

5 Department of Ophthalmology, Yijishan Hospital of Wannan Medical College, Wuhu 241000, China 